\title{
Nuclease activities and cell death processes associated with the development of surface cultures of Streptomyces antibioticus ETH 7451
}

\author{
Marisol Fernández and Jesús Sánchez
}

Area de Microbiología, Departamento de Biologia Funcional, Facultad de Medicina, 33006 Oviedo, Spain
Author for correspondence: Jesús Sánchez. Tel: +34 985103555. Fax: +34 985103148. e-mail:JSM@sauron.quimica.uniovi.es

The presence and significance of developmentally regulated nucleases in Streptomyces antibioticus ETH 7451 has been studied in relation to the lytic processes occurring during differentiation. The cell-death processes have been followed in surface cultures by a propidium iodide viability assay. This has allowed the visualization of dead (membrane-damaged, red fluorescent) and live (membrane-intact, green fluorescent) mycelium during development, and has facilitated the analysis of the role of nucleases in these processes. A parallel activity-gel analysis showed the appearance of 20-22 kDa, $34 \mathrm{kDa}$ and $44 \mathrm{kDa}$ nucleases, the latter appearing only when aerial mycelium is formed. The appearance of these nucleases shows a remarkable correlation with the death process of the mycelium during differentiation and with chromosomal DNA degradation. The 20-22 kDa enzymes are possibly related to the lytic phenomena taking place in the vegetative substrate mycelium before the emergence of the reproductive aerial mycelium, whereas the function of the $44 \mathrm{kDa}$ nuclease seems to be related to the sporulation step. The 20-22 kDa nucleases require $\mathrm{Ca}^{2+}$ for activity and are inhibited by $\mathrm{Zn}^{2+}$. The nucleases are loosely bound to the cell wall from where they can be liberated by simple washing. Conceivably, these enzymes work together and co-ordinate to achieve an efficient hydrolysis of DNA from dying cells. The results show that the biochemical reactions related with the lytic DNA degradation during the programmed cell death are notably conserved in Streptomyces. Some of the features of the process and the biochemical characteristics of the enzymes involved are analogous to those taking place during the DNA fragmentation processes in eukaryotic apoptotic cells.

Keywords: programmed cell death, substrate mycelium, chromosomal DNA degradation, viability staining, differentiation

\section{INTRODUCTION}

The cell cycle best characterized of all the actinomycetes is that of Streptomyces, a genus with outstanding biotechnological importance: about two thirds of the antibiotics and other secondary metabolites of interest in medicine and agriculture are produced by this genus (Baltz, 1998). In Streptomyces the exponential growth phase coincides with the vegetative phase, which is characterized by the presence of hyphae with few septa between the cells. Next an aerial mycelium phase occurs,

Abbreviation: PI, propidium iodide. which is made up of thicker hydrophobic hyphae perpendicular to the surface. These suffer a massive septation and segregation of the genetic material, forming compartments which will finally give rise to spores. The intracellular effectors connecting the environmental signals with the regulatory genes are not well known, although it is conceivable that changes in particular metabolites are a determinant for the onset of the differentiation (Chater, 1998). The aerial growth of Streptomyces follows a period of decrease in the synthesis of macromolecules (Granozzi et al., 1990) and in fact, the formation of aerial mycelium coincides with a massive death in the substrate mycelium, which contributes to the nutrient support of the aerial hyphae 
(Mendez et al., 1985). The dead hyphae stay forming part of the structure of the colony, and serve as support for the aerial mycelium (Miguelez et al., 1999). The cell wall also remains undisturbed, providing in this way a mechanical support for the development of the aerial hyphae and serving as a conducting system for the translocation of nutrients (Miguelez et al., 1999). Experimental support was previously obtained for the recycling of the substrate mycelium proteins of Streptomyces antibioticus ATCC 11891 (Miguelez et al., 1999).

The hyphae of S. antibioticus undergo an orderly process of internal cell dismantling, including extensive genome digestion, that resembles the programmed cell death in animal development (Miguelez et al., 1999). Our group has been interested in clarifying the mechanisms that intervene in the reuse of the above-mentioned DNA constituents. With this purpose in mind we previously analysed the presence of nucleolytic activities that could play a role in such processing in S. antibioticus ATCC 11891. Initially, we detected and purified a nutritionally regulated $29 \mathrm{kDa}$ periplasmic nuclease that nicks double-stranded DNA at $\mathrm{dG} / \mathrm{dC}$-rich sequences, leaving 35-250 bp end products with $3^{\prime}$-hydroxyl and $5^{\prime}$-phosphate termini (Cal et al., 1995). We then detected two main exocellular nucleases of 18 and $34 \mathrm{kDa}$, which were, as in the former, nutritionally regulated (i.e. they did not appear in rich media, which repress differentiation). Their biochemical characteristics made them suitable for the degradation and recycling of the DNA building blocks, as for example their lack of specificity on cutting DNA sequences and the formation of 5 '-phosphate mononucleotides as predominant end products (Nicieza et al., 1999). These enzymes show a dependence on $\mathrm{Ca}^{2+}$ for their activity and co-operate efficiently with the periplasmic nuclease to completely hydrolyse the DNA. In the present work we carry out such an analysis during the differentiation of $S$. antibioticus ETH 7451, a strain which is also currently being investigated by our group due to its remarkable capability to sporulate in submerged conditions (Novella et al., 1992). This will facilitate the physiological analysis of the death process. We started our investigations in this strain by following the process of the mycelium death in cultures growing on agar, in order to subsequently compare this with the cell death processes taking place in submerged cultivation. To achieve this, we applied a propidium iodide viability stain technique, which allowed us to show the damage to the cytoplasmic membrane. In this way we have shown the evolution of the cell death processes in relation to the appearance of the nucleases and chromosomal DNA degradation. The main role in the substrate DNA hydrolysis is probably performed by $20-22 \mathrm{kDa}$ nucleases, which seem to be the equivalent of the previously described $18 \mathrm{kDa}$ nuclease from $S$. antibioticus ATCC 119891 (Nicieza et al., 1999). We also report a $44 \mathrm{kDa}$ nuclease, not described previously, which appears when the aerial mycelium is formed. In conditions in which the nuclease activities are inhibited, such as in the presence of $\mathrm{Zn}^{2+}$, the chromosomal DNA appears less degraded. The nucleases are loosely bound to the cell wall from where they can be liberated by simple washing. The results show that the function of these enzymes is likely conserved within Streptomyces and lend further support to the possible role of the specific activities in development.

\section{METHODS}

Organism and culture conditions. S. antibioticus ETH 7451 was grown in Petri dishes with GYM medium (glucose, yeast extract, malt extract; Novella et al., 1992). Plates were directly inoculated with a dense spore suspension to obtain confluent growth. Where indicated, plates were covered with sterile cellophane disks of the same diameter, before inoculation. In the inhibition experiments, an aqueous solution of 0.5 and $1 \mathrm{mM} \mathrm{ZnCl}_{2}$ (1 ml) or water (control) was added directly to the plates after 5-6 h incubation.

Viability assay. A permeability assay similar to that described previously for submerged Streptomyces cultures was used (Fernández \& Sánchez, 2001). This involves the staining of damaged (leaky) cells with a polar (cell-impermeant) stain (propidium iodide, PI) in order to detect the dead cell population of $S$. antibioticus. GAE plates prepared with Noble agar (Difco) and inoculated as described above were used to obtain blocks of the GAE agar with a scalpel. These were further trimmed to cubes of about $7 \mathrm{~mm}$ in size and introduced into a microtome (11 $\mathrm{mm}$ hole diameter) previously cooled to $4{ }^{\circ} \mathrm{C}$, with the growth surface side-oriented. Sections of about $0 \cdot 3-0.4 \mathrm{~mm}$ were obtained with a razor blade, deposited in the same orientation on a clean slide and covered with a SYTO 9 plus PI (LIVE/DEAD BacLight Bacterial Viability Kit; Molecular Probes, L-13152) stain mix prepared as recommended by the manufacturer $(1: 1, \mathrm{v} / \mathrm{v})$. The SYTO 9 green fluorescent nucleic acid stain labels all the cells, that is, those with intact membranes and those with damaged ones. The PI red fluorescent nucleic acid stain only enters the damaged Streptomyces cells (Fernandez \& Sanchez, 2001), causing a reduction in the SYTO 9 stain because of its higher nucleic acid affinity. After staining for at least $10 \mathrm{~min}$ in the dark, the sample was observed under a Bio-Rad MRC600 laser confocal microscope, at 488 and $568 \mathrm{~nm}$ excitation and 530 (green) or $630 \mathrm{~nm}$ (red) emission. Both images were mixed with the Confocal Assistant version 4.02 program (Todd Clark Brelje, 19941996, freeware program distributed by Bio-Rad Laboratories) in order to make up the final dual-colour image.

Nuclease activity gel and protein analysis. Nuclease activities were analysed in samples obtained at the three developmental stages: substrate mycelium, aerial mycelium and sporulation. Samples were obtained in three different ways: in one of them, the bacterium was grown directly on the agar surface and the agar was extruded by forcing it through the hole of a plastic syringe (Nicieza et al., 1999). The resulting suspension was centrifuged at $4{ }^{\circ} \mathrm{C}$, for $30 \mathrm{~min}$ at $17000 \mathrm{~g}$ and the supernatant used as the source of the enzyme. In other samples the mycelium was grown on the surface of cellophane disks, and was scraped out with a plain spatula, resuspended in $20 \mathrm{mM}$ Tris/HCl pH 8.0, $1 \mathrm{mM}$ EDTA, $7 \mathrm{mM}$ 2-mercaptoethanol buffer and ruptured in an MSE Soniprep 150, in 6 cycles of $10 \mathrm{~s}$, on ice. After centrifuging at 10000 r.p.m. (Eppendorf 5415C microcentrifuge) for $30 \mathrm{~min}$ at $4{ }^{\circ} \mathrm{C}$, the supernatant was used as the source of the activity. Finally, in other experiments the mycelium collected from the cellophane disks as mentioned above was shaken for about $10 \mathrm{~min}$ in a Vortex before analysing the activity. To avoid differences in the results (due to the different sizes of the collected samples), we processed 
identical agar volumes in the extruded samples. For the sonicated and shaken samples, the weight/buffer volume relationships or the amount of protein were identical. The bands corresponding to the different nuclease activities were visualized in each sample by measuring the 'in situ' DNA hydrolysis after separating the proteins in denaturing SDSpolyacrylamide gels containing denatured DNA (heated at $100{ }^{\circ} \mathrm{C}$ for $10 \mathrm{~min}$ and then chilled on ice) (Rosenthal \& Lacks, 1977). After the electrophoresis the proteins were renatured and the activity detected in $20 \mathrm{mM}$ Tris/ $\mathrm{HCl}$ $\mathrm{pH} 8.0,7 \mathrm{mM}$ 2-mercaptoethanol, $10 \mathrm{mM} \mathrm{MgCl}_{2}, 5 \mathrm{mM}$ $\mathrm{CaCl}_{2}, 10 \%$ DMSO buffer, as reported elsewhere (Nicieza et al., 1999). Gels were incubated for $90 \mathrm{~min}$ to $3 \mathrm{~h}$ at $37^{\circ} \mathrm{C}$. Micrococcal nuclease and bovine pancreatic DNase I (Amersham Pharmacia) were used as controls. Proteins were analysed by SDS-PAGE in $12 \%$ polyacrylamide gels (Laemmli, 1970) after mixing the above samples with sample buffer (M. Fernandez \& J. Sanchez, unpublished results) and heating at $100^{\circ} \mathrm{C}$ for $5 \mathrm{~min}$ before loading. Proteins were stained with silver (Cal et al., 1995). Molecular masses were estimated by their mobility with reference to marker proteins (Low Range, Bio-Rad).

DNA fragmentation assay. DNA degradation in the mycelium of $S$. antibioticus ETH 7451 was analysed in samples collected from cellophane discs after a careful extraction and subsequent agarose gel electrophoresis. The mycelium was suspended in Tris/ $\mathrm{HCl} \mathrm{pH} \mathrm{8} \cdot 0,1 \mathrm{mM}$ EDTA (TE buffer), $\mathrm{pH} 8.0$ plus $2 \mathrm{mg}$ lysozyme $\mathrm{ml}^{-1}$ and incubated at $30^{\circ} \mathrm{C}$ for $1 \mathrm{~h}$. Then EDTA $(100 \mathrm{mM}$ final concn) and proteinase $\mathrm{K}$ (50 $\mu \mathrm{g} \mathrm{ml}^{-1}$ final concn; Roche Molecular Biochemicals) were added and the sample incubated at $30^{\circ} \mathrm{C}$ for $5 \mathrm{~min}$. SDS $(1 \%$, final) was added and the samples incubated further for $2 \mathrm{~h}$ at $37^{\circ} \mathrm{C}$. An equal volume of phenol/chloroform (1:1) was added and mixed carefully. After centrifugation at $11000 \mathrm{~g}$ for $5 \mathrm{~min}$, the aqueous phase was collected. The process was repeated until a completely clean aqueous solution was obtained. DNA was precipitated with $0 \cdot 1$ vol. $3 \mathrm{M}$ sodium acetate and 1 vol. 2-propanol, washed by centrifugation with $70 \%$ ethanol and resuspended in TE. RNase A $\left(100 \mu \mathrm{g} \mathrm{ml}^{-1}\right)$ and RNase $\mathrm{T}_{1}\left(1000 \mathrm{U} \mathrm{ml}^{-1}\right)$ (Sigma) were added and the solution incubated for $2 \mathrm{~h}$ at $37^{\circ} \mathrm{C}$. The phenol/chloroform extraction, precipitation and washing were repeated as above. The DNA was analysed by $0.8 \%$ agarose gel electrophoresis and stained with SYBR gold nucleic acid gel stain (Molecular Probes) which presents more than tenfold sensitivity over the previously used ethidium bromide (Nicieza et al., 1999). The gels were visualized on a $300 \mathrm{~nm}$ UV transilluminator and photographed with a Polaroid 667 black-and-white print film and a photographic filter (S-7569; Molecular Probes). The nature of the fluorescent band was confirmed by digestion with DNase I $\left(0 \cdot 1 \mu \mathrm{g} \mu \mathrm{l}^{-1}\right)$ for $2 \mathrm{~h}$ at $37^{\circ} \mathrm{C}$.

\section{RESULTS}

\section{Viability staining of the Streptomyces colonies}

S. antibioticus ETH 7451 appears transparent and slightly orange-dark on the plates of GYM medium. The phase of substrate (vegetative) mycelium is unusually short (about $9 \mathrm{~h}$ ) and is followed by the appearance of a thick opaque white layer (formed by aerial mycelium) projecting from the substrate mycelium. After $24 \mathrm{~h}$ the surface is completely covered by a grey layer of a dense mass of spores. Assays of viability were carried out at the different developmental phases. The SYTO 9 plus PI stain gives an outstanding view of the vegetative hyphae
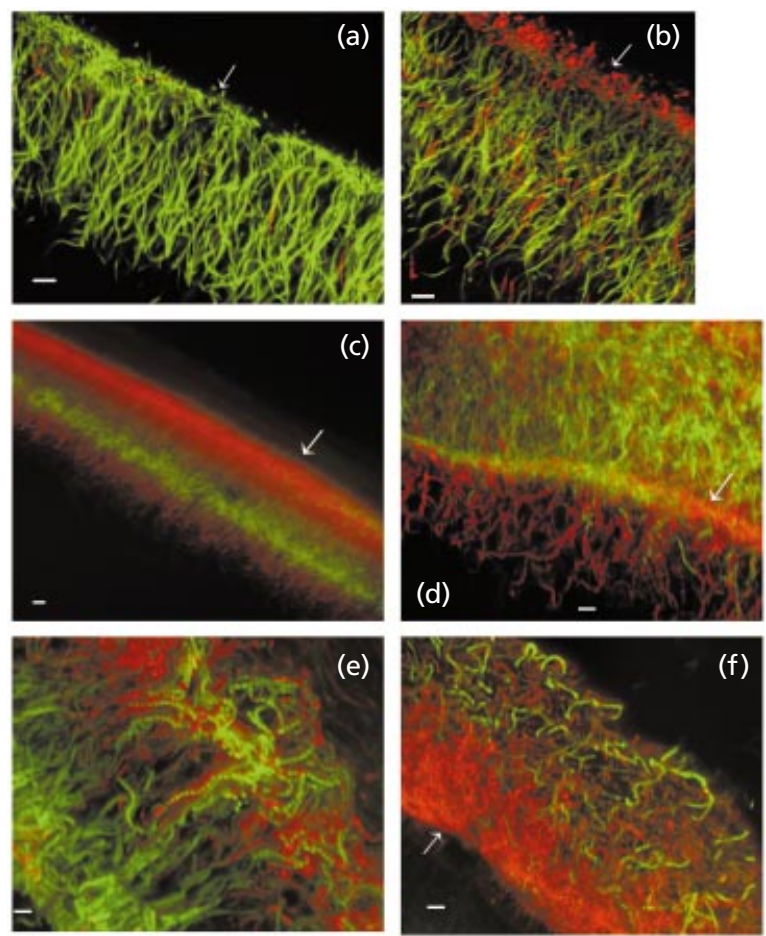

Fig. 1. Laser confocal microscopy of $S$. antibioticus ETH 7451 cultures growing on GYM plates. (a) Substrate mycelium after 6 h; (b) $8 \mathrm{~h}$ substrate mycelium; (c) $9 \mathrm{~h}$ substrate mycelium; (d) $12 \mathrm{~h}$ substrate (red) and developing (green) aerial mycelium; (e, f) $15 \mathrm{~h}$ aerial mycelium and spores. Arrows show the agar border. Bars, $10 \mu \mathrm{m}$.

embedded in the agar (Fig. 1). At the phase of vegetative (substrate) mycelium $(6 \mathrm{~h})$ the hyphae appear greenfluorescent, indicating that the membrane is intact (Fig. 1a). When the culture develops (about 6-9 h), redfluorescent membrane-damaged hyphae are observed within the substrate mycelium embedded in the agar, together with a red layer of substrate mycelium in the upper zone of the agar surface (Fig. 1b). By $9 \mathrm{~h}$, some zones of the plate cultures appear completely red both on the surface and within the agar (not shown). In other areas a green layer of mycelium can be observed within the internal red layer of mycelium (Fig. 1c). The thickness of the upper red area can vary from sample to sample in the same culture, sometimes appearing thinner and the green-fluorescent layer thicker (not shown). Aerial mycelium start to develop after $12 \mathrm{~h}$, on the upper layer of red hyphae (Fig. 1d), showing a deep agar zone with a membrane-compromised substrate mycelium and an upper green-fluorescent hyphae layer which should correspond to an incipient aerial mycelium. As the aerial mycelium development continues, two different regions can be observed: a green layer in the lower part of the sample (nearer to the agar surface) and a red network in the bulk of the air-projecting mycelia with live spore chains interwoven within the red layer (Fig. 1e). In more mature zones, all aerial mycelium appear red-fluorescent; only the chains of newly formed spores are viable (Fig. 1f). 
(a)

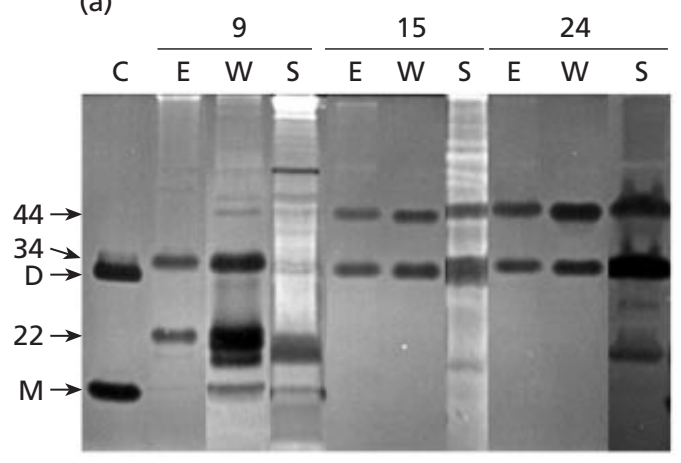

(b)

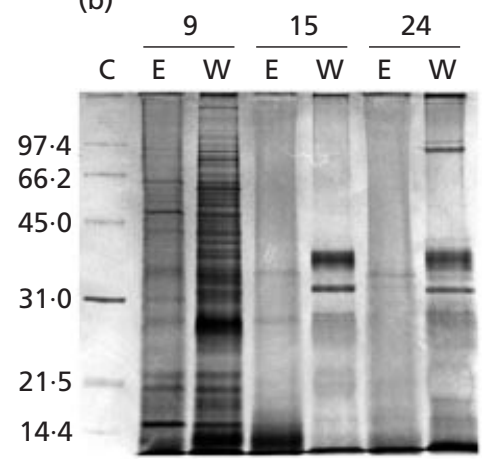

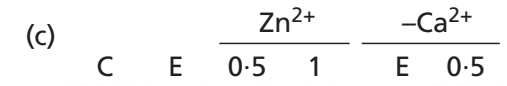

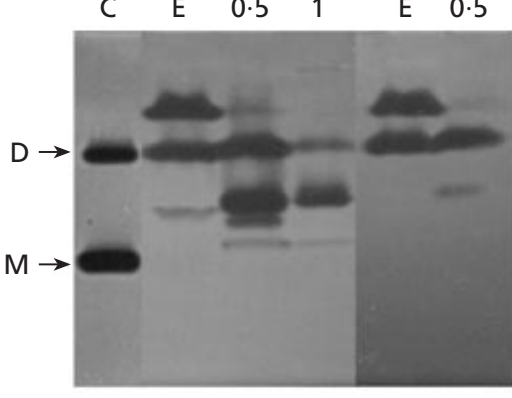

(d)

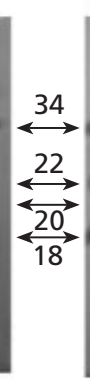

d)

(e)

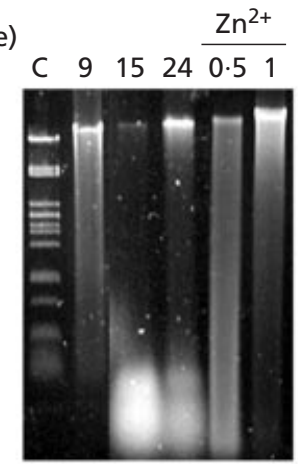

Fig. 2. Activity gel, protein and DNA fragmentation analysis of samples from $S$. antibioticus ETH 7451 growing in GYM plates. (a) Samples from 9, 15 and $24 \mathrm{~h}$ were analysed for the presence of nuclease bands in the extruded agar (E), washed mycelium collected from cellophane (W) and sonicated mycelium collected from cellophane (S). C, molecular mass controls: micrococcal nuclease $(M, 16 \cdot 7 \mathrm{kDa})$ and DNase I (, $31 \mathrm{kDa})$. (b) SDS-PAGE and silver staining of proteins from the extruded (E) and washed (W) samples after 9, 15 and $24 \mathrm{~h}$. C, molecular mass standards (phosphorylase $b$, bovine serum albumin, ovalbumin, carbonic anhydrase, trypsin inhibitor, lysozyme). (c) Activity gel analysis of the extruded agar samples from $15 \mathrm{~h}$ cultures developed in the absence $(\mathrm{E})$ and presence of $0.5 \mathrm{mM}$ and $1 \mathrm{mM} \mathrm{Zn}^{2+}$. $-\mathrm{Ca}^{2+}$ lanes used the same samples $\left(\mathrm{E}\right.$ and $0.5 \mathrm{mM} \mathrm{Zn}^{2+}$ ) but $\mathrm{Ca}^{2+}$ was omitted from the incubation buffer in the activity gel analysis. Molecular mass controls (C) were as in (a). (d) Effect of $\mathrm{Zn}^{2+}$ on the nuclease activities. Samples of the above extruded agar developed in the presence of $0.5 \mathrm{mM} \mathrm{Zn}^{2+}$ were incubated for $3 \mathrm{~h}$ in the absence $(E)$ and presence of $0.5 \mathrm{mM}$ and $1 \mathrm{mM} \mathrm{Zn}{ }^{2+}$. (e) Agarose gel electrophoresis of DNA isolated from the mycelium grown on cellophane at 9,15 and $24 \mathrm{~h}$ and stained with SYBR gold nucleic acid gel stain; $0.5 \mu \mathrm{g}$ (9 h sample) and $4 \mu \mathrm{g}$ ( 15 and $24 \mathrm{~h}$ samples) DNA were loaded in the gel. $\mathrm{Zn}^{2+}$ lanes, DNA $(4 \mu \mathrm{g})$ isolated from $24 \mathrm{~h}$ cellophane cultures developed in the presence of $0.5 \mathrm{mM}$ and $1 \mathrm{mM} \mathrm{ZnCl} 2$. , Pstl-digested lambda DNA.

\section{Appearance and characteristics of the nucleases and chromosomal DNA fragmentation in the course of development}

Nuclease activities were analysed in samples of plate cultures of S. antibioticus ETH 7451 at the three stages of development: substrate mycelium, aerial mycelium and sporulation. Each of these were processed in three different ways as specified in Methods. In the first, the agar from plates in which the bacterium was growing directly on the surface was extruded by forcing it through the hole of a plastic syringe; while the mycelium remained intact, this treatment disrupted the structure of the gel and the proteins could be recovered in the supernatant after centrifugation. This method permits the analysis of the nucleases excreted by the mycelium into the surrounding agar. In another series of samples, the mycelium grown on the surface of cellophane disks was scraped with a plain spatula and ruptured to analyse the intracellular nuclease activity. Finally, in a third series of experiments, the mycelium grown on the cellophane disks was collected in a buffer (see Methods) and shaken. All the samples thus obtained were analysed for nuclease activity in DNA-polyacrylamide gels. By these combined analyses a complete view of the nucleases and their distribution was obtained (Fig. 2).

Two main bands of $34 \mathrm{kDa}$ and $\sim 22 \mathrm{kDa}$ were detected at $9 \mathrm{~h}$ of cultivation (no activity was detected at $6 \mathrm{~h}$; data not shown), but their intensity was higher in the washed mycelium sample (Fig. 2a). In addition, another $\sim 20 \mathrm{kDa}$ (and a minor $18 \mathrm{kDa}$ band) band appears in the washed mycelium. The 20 and $22 \mathrm{kDa}$ bands could be different forms of the same nuclease, as both show a strict requirement of $\mathrm{Ca}^{2+}$ for their activity (Fig. 2c). The $34 \mathrm{kDa}$ nuclease does not have such a strict requirement as the $20-22 \mathrm{kDa}$ nucleases (Fig. 2c). In the sonicated mycelium, the two 20 and $22 \mathrm{kDa}$ bands are again visible (the higher intensity in this case corresponds to the $20 \mathrm{kDa}$ band) in addition to one thin $54 \mathrm{kDa}$ band and 
the scarcely visible $18 \mathrm{kDa}$ band. The chromosomal DNA appears already partially degraded at this time (Fig. 2e). When the aerial mycelium developed completely (15 h samples), the $20-22 \mathrm{kDa}$ bands could not be distinguished, but the $34 \mathrm{kDa}$ band plus a $44 \mathrm{kDa}$ band were clearly seen (a fine $20 \mathrm{kDa}$ band can be also seen in the sonicated mycelium; Fig. 2a). The $44 \mathrm{kDa}$ nuclease, as with the $34 \mathrm{kDa}$ enzyme, does not require $\mathrm{Ca}^{2+}$ for the activity (Fig. 2c). At this point, a very extensive degradation of chromosomal DNA is observed; only a fraction of the DNA appears intact in the upper part of the gel, the rest being fragments of approximately $100-250 \mathrm{~kb}$ (Fig. 2e). Similar results were obtained in the sporulation phase $(24 \mathrm{~h})$, in which aerial mycelium continued to form, but the intensity of the $44 \mathrm{kDa}$ nuclease is somewhat higher. The aspect of the chromosomal DNA on the gel is similar to the $15 \mathrm{~h}$ sample (Fig. 2e), although the fraction which migrates more slowly on the gel is higher. The $34 \mathrm{kDa}$ nuclease was present in all the developmental steps. The fact that the above nucleases can be washed away from the cells by moderate shaking of the intact mycelium and also detected in the extruded agar samples indicates that they are externally located and loosely bound to the cell wall. This is supported by the comparatively high nuclease activity present in the washed-mycelium samples (Fig. 2a).

As previously reported for S. antibioticus ATCC 11891 (Nicieza et al., 1999), the development of S. antibioticus ETH 7451 is impaired in the presence of $0.5-1 \mathrm{mM}$ $\mathrm{Zn}^{2+}$. This means that whereas in the control cultures at $15 \mathrm{~h}$ the aerial mycelium is completely formed, the cultures with $\mathrm{Zn}^{2+}$ are retarded in the phase of substrate mycelium. After $24 \mathrm{~h}$, the control cultures have sporulated; the plates with $\mathrm{Zn}^{2+}$ are in the aerial mycelium phase, with no sign of septation within the hyphae (not shown). When the nucleases were analysed in the extruded agar samples from both media at $15 \mathrm{~h}$, the control cultures showed the presence of the $34 \mathrm{kDa}$ and $45 \mathrm{kDa}$ bands (Fig. 2c) ; however, in the cultures with 0.5 and $1 \mathrm{mM} \mathrm{Zn}{ }^{2+}$ the $20-22 \mathrm{kDa}$ band (the $20 \mathrm{kDa}$ band

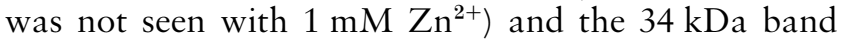
were visible. The gel activity analysis was repeated with the extruded agar sample from the $0.5 \mathrm{mM} \mathrm{Zn^{2+ }}$ plates (see Fig. 2c) but in this case $0.5 \mathrm{mM}$ and $1 \mathrm{mM} \mathrm{Z \textrm {Zn } ^ { 2 + }}$ were added to the incubation buffer. The results (Fig. $2 \mathrm{~d}$ ) show that the activity of the three $20-22$ and $34 \mathrm{kDa}$ nucleases is inhibited by $\mathrm{Zn}^{2+}$, although the $20-22 \mathrm{kDa}$ nucleases seem more sensitive than the $34 \mathrm{kDa}$ enzyme; the $18 \mathrm{kDa}$ band present in the control is not affected. It can be concluded that it is the activity, and not the synthesis of the enzymes, which is inhibited by $\mathrm{Zn}^{2+}$. This inhibition is likely to be responsible for the fact that in the $24 \mathrm{~h}$ cultures the chromosomal DNA appears less degraded in the presence of 0.5 and $1 \mathrm{mM}$ $\mathrm{Zn}^{2+}$, when the control cultures are sporulated and the DNA is substantially degraded (Fig. 2e; see above).

An SDS-PAGE analysis of the proteins of the washed substrate (vegetative) mycelium from $S$. antibioticus ETH 7451 showed a remarkably high proportion of proteins loosely bound to it (Fig. 2b). This suggests that the surface, and most likely the cell wall from the vegetative mycelium is a functionally very active structure which maintains a notable reservoir of proteins, some or most of them probably related with scavenger and/or degradative functions. These cell-wall located proteins are drastically reduced in number in the aerial mycelium and, in fact, only a few predominant proteins ( $33 \mathrm{kDa}$ and $38 \mathrm{kDa}$ ) are observed at $15 \mathrm{~h}$ in the washed S. antibioticus ETH 7451 mycelium (Fig. 2b). These two proteins plus another of about $86 \mathrm{kDa}$, and minor bands of $42 \mathrm{kDa}$ and $36 \mathrm{kDa}$ are all that can be seen in the sporulation phase gels (Fig. 2b). This will notably facilitate the purification and biochemical characterization of the nucleases and the subsequent cloning of the genes.

\section{DISCUSSION}

\section{Analysis of the viability of substrate and aerial mycelium of $S$. antibioticus}

The viability test has been recently applied by our group to Streptomyces submerged cultures (Fernandez \& Sanchez, 2001). In this study it has been used for the first time in cultures growing on the surface. The technique has shown its outstanding feasibility for evaluating the physiological state of the mycelium of Streptomyces growing on the agar surface. This type of analysis will constitute a valuable complement of other biochemical or morphological studies. The ultrastructural studies of the colony, such as those performed previously in $S$. antibioticus ATCC 11891 (Miguelez et al., 1999), report the internal details of the particular hyphae (as for example the progression of nucleoid degradation or the changes in the cytoplasm) whereas the viability method contributes by providing the real view of the general physiological state of the colony. For example, it has been claimed that nucleoid degradation is an early event in the hyphal death process and that this degradation precedes the rupture of the plasma membrane (Miguelez et al., 1999). However, this is only based on the ultrastructural aspect of the nucleoid within specific hyphae (i.e. a disorganization of the electron-dense nucleoid and a continuous well-stained membrane structure). Whereas the internal disorganization of some hyphae could coexist with a relative integrity of the plasma membrane, what seems clear is that at the stage at which the nucleolytic processes conceivably take place (shortly before and during aerial formation and sporulation steps) both the presence of the nucleases and the presence of massively membrane-damaged hyphae coexist (Fig. 1b-f; Fig. 2a). As mentioned in the Results, no nuclease activity was detected at $6 \mathrm{~h}$ cultivation. During this time the membrane, as shown by the viability staining (Fig. 1a) remains intact. Apart from this, the above-mentioned ultrastructural analysis of the cell death process carried out in surface cultures (Miguelez et al., 1999) shows remarkable analogies with our viability results in S. antibioticus ETH 7451. As also shown here, two rounds of hyphal death were previously 
described by the above authors in S. antibioticus ATCC 11891, the first round coinciding with the formation of aerial mycelium (which should correspond to the death phases shown in Fig. 1b-d). This massive death of the substrate mycelium does not hinder the emergence of the aerial hyphae, as occurs in our study (see Fig. 1d). The second round takes place when sporulation starts and affects the nonsporulating parts of the aerial hyphae (Fig. 1e, f). At the end, the S. antibioticus substrate mycelium appears empty and all nonsporulating aerial hyphae degenerate and die (Miguelez et al., 1999), this phenomenon being maximally abundant towards the boundary with the substrate mycelium (as also shown in the stained sample in Fig. 1f). The utility of the analysis by fluorescence confocal microscopy described in our work extends far from the phenomenon analysed here, as it opens the possibility to investigate the influence of the medium and nutritional conditions on the viability state of this biotechnologically relevant group of bacteria.

\section{Nuclease production, chromosomal DNA degradation and differentiation are co-ordinated events}

The impairment of the aerial mycelium formation by $\mathrm{Zn}^{2+}$ could be due to additional effects of this cation on other enzymes, for example the serine proteases. A trypsin-like enzyme has been described in S. antibioticus ATCC 11891 (Nicieza et al., 1999) and a similar protease has been also detected in S. antibioticus ETH 7451 (M. Fernandez, unpublished results). Its role has been related to proteolytic processing of a hypothetical inactive precursor of the $18 \mathrm{kDa}$ and/or the $34 \mathrm{kDa}$ nucleases (Nicieza et al., 1999; J. Huergo \& J. Sanchez, unpublished results). The $20-22 \mathrm{kDa}$ nucleases seem to be equivalent to the $18 \mathrm{kDa}$ nuclease detected previously in the surface-sporulating strain S. antibioticus ATCC 11891. In our previous work (Nicieza et al., 1999) we reported that the $18 \mathrm{kDa}$ nuclease peaks in the aerial mycelium phase (about $36 \mathrm{~h}$ ). This apparent difference with respect to the results obtained in the ETH 7451 strain can be readily explained by the difference in the growth kinetics between the two strains. The development of S. antibioticus ATCC 11891 is slower than the ETH 7451 strain and thus, the phase of substrate (vegetative) mycelium in the ATCC 11891 strain lasts about $24 \mathrm{~h}$. It is conceivable that both vegetative and aerial mycelium coexist at $48 \mathrm{~h}$, whereas in the ETH 7451 strain, which develops significantly more rapidly, only vegetative or aerial mycelium would predominate at each phase (as suggested by the photographs in Fig. $1 \mathrm{e}, \mathrm{f})$. This could explain the higher intensity of the $18 \mathrm{kDa}$ nuclease band in the activity gels from the aerial mycelium phase of $S$. antibioticus ATCC 11891. The similarity between the $18 \mathrm{kDa}$ and the $20-22 \mathrm{kDa}$ nucleases is further supported by the fact that the ETH 7451 enzyme shows, as occurred with the ATCC 11891 $18 \mathrm{kDa}$ nuclease (Nicieza et al., 1999), a strict requirement for $\mathrm{Ca}^{2+}$. The activity of the $44 \mathrm{kDa}$ and $34 \mathrm{kDa}$ nucleases, by contrast, is not noticeably impaired in the absence of that cation [this is also true for the $S$. antibioticus ATCC $1189134 \mathrm{kDa}$ nuclease, which was previously claimed to need $\mathrm{Ca}^{2+}$ (Nicieza et al., 1999; J. Huergo \& J. Sánchez, unpublished results)]. Moreover, the $20-22 \mathrm{kDa}$ nucleases are synthesized only in the vegetative (substrate) mycelium (plates incubated for $9 \mathrm{~h}$ ) and could play, as postulated in the above strain for the $18 \mathrm{kDa}$ nuclease (Nicieza et al., 1999), a preferential role in the DNA lytic processes which conceivably take place in the substrate mycelium just before and during the course of emergence of the aerial mycelium. This hydrolysis is likely facilitated by the disorganization of the cytoplasmic membrane, as mentioned above, and shown by the viability stain (Fig. 1c, d). The role of these nucleases and possibly the $34 \mathrm{kDa}$ enzyme, in the substrate mycelium DNA degradation, is further supported by the delaying of the chromosomal DNA hydrolysis in the presence of $\mathrm{Zn}^{2+}$ (Fig. 2e). The $44 \mathrm{kDa}$ nuclease appears specifically at the aerial mycelium phase; when the appearance of the aerial mycelium is impaired by $\mathrm{Zn}^{2+}$, the nuclease is not visible (but the 20-22 kDa enzymes are present; Fig. 2c), thus supporting the relationships between the synthesis of the enzyme at the differentiation phase and its potential role in the lytic processes which take place in the aerial mycelium before spore formation. A nuclease of similar molecular mass has been recently detected in the previously studied S. antibioticus ATCC 11891 strain (M. Fernández \& J. Sánchez, unpublished results). This enzyme, as shown here, appears specifically when the aerial mycelium is forming (M. Fernández \& J. Sánchez, unpublished results). The $34 \mathrm{kDa}$ nuclease could be related to both lytic processes, probably contributing to the concerted activity of the mentioned nucleases to a rapid and extremely efficient degradation of the DNA, as has been shown previously with the $18 \mathrm{kDa}$ and $34 \mathrm{kDa}$ enzymes from S. antibioticus ATCC 11891 (Nicieza et al., 1999).

Chromosomal DNA appears partially degraded when aerial mycelium starts to form in S. antibioticus ATCC 11891 growing on plates (Nicieza et al., 1999). In the sporulation phase the DNA degradation is much more intense (Nicieza et al., 1999). These kinetics are also observed in S. antibioticus ETH 7451 (Fig. 2e). When the aerial mycelium is completely formed $(15 \mathrm{~h})$ the DNA is extensively degraded, with the exception of a small slowly migrating fraction visible as a defined band on the agarose gel. This likely represents the DNA of the few spores present at this time, which are partially sensitive to lysozyme (Novella et al., 1992). This band, although more intense, is also seen in the $24 \mathrm{~h}$ sporulated cultures. The remaining DNA visible on the gel is completely degraded to $100-250 \mathrm{~kb}$ fragments; the smaller oligonucleotides and mononucleotides conceivably formed in the hydrolysis (Nicieza et al., 1999) will not be recovered by the 2-propanol/sodium acetate step and thus are not visible on the gel. As already pointed out, S. antibioticus ETH 7451 has been previously used in our group to analyse differentiation, as it has an exceptional capability to sporulate synchronously after a nutritional down-shift under submerged conditions (Novella et al., 1992). The bacteria harbour a NaeI- 
isoschizomer restriction-modification system (Fernández et al., 1998; A. Godany, unpublished results) and is remarkably resistant to actinophages (J. Sánchez, unpublished data). We are currently performing a study of the appearance and biochemical characteristics of the nucleases during submerged development, in order to analyse the physiological significance of both surface and submerged differentiation processes. The results available show that the biochemical characteristics of the $20-22 \mathrm{kDa}$ and $34 \mathrm{kDa}$ nucleases $(\mathrm{NaCl}, \mathrm{KCl}$ or $\mathrm{Zn}^{2+}$ inhibition, preference for single or double-stranded DNA, $\mathrm{Mg}^{2+}$ and $\mathrm{Ca}^{2+}$ requirements) are identical to the surface nucleases and the $18 \mathrm{kDa}$ and $34 \mathrm{kDa}$ nucleases previously described in S. antibioticus ATCC 11891 (M. Fernández \& J. Sánchez, unpublished results).

\section{Streptomyces as a developmental model}

These and our previous data (Nicieza et al., 1999) point to the existence of a series of co-ordinated and notably conserved biochemical events, related to chromosomal DNA degradation during the lytic processes that accompany development and differentiation in Streptomyces. In the hypothetical sequence for cell death induction, a change in the nutritional environment, growth rate or both, will transmit a still uncertain signal to the Streptomyces cells which in turn could activate a cytoplasmic effector (perhaps with the co-operation of $\mathrm{Ca}^{2+}$, protein kinases or even caspase-like proteases (Smith, 1995; Zhang, 1996; Aravind et al., 1999). This could trigger mycelial cell death and the lytic processes. The formation of the nucleases which intervene in the DNA degradation process is conceivably under a strict control, part of which could be the induction of the above-mentioned proteolytic processing of an inactive high molecular mass precursor which would give rise to the active 18 and $34 \mathrm{kDa}$ nuclease forms (Nicieza et al., 1999; J. Huergo \& J. Sánchez, unpublished results). A second round of DNA hydrolysis could take place in the aerial mycelium, when spores are forming. In this, the $44 \mathrm{kDa}$ enzyme plus the $34 \mathrm{kDa}$ nuclease could play the role. We have investigated the existence of nucleases with the characteristics and location of those described here, in several other species of Streptomyces, such as Streptomyces coelicolor, Streptomyces albus, Streptomyces achromogenes or Streptomyces lividans; our initial results show the presence, in all of them, of $34 \mathrm{kDa}$ and $18-23 \mathrm{kDa}$ cell-wall located nucleases (no activity could be detected within the cytoplasm) with similar biochemical characteristics to those described here and in S. antibioticus ATCC 11891 (J. Huergo \& J. Sánchez, unpublished results).

It has been suggested that micro-organisms which present a complex developmental life (such as Streptomyces, Bacillus, Anabaena, Caulobacter, Rhizobium or the myxobacteria) would have programmed cell death mechanisms which could be considered as the phylogenetic precursors of the eukaryotic programmed cell death (Yarmolinsky, 1995; Hochman, 1997). This has been shown for $S$. antibioticus, in which an orderly process of internal cell dismantling, rather than an uncontrolled autolytic process, takes place (Miguelez et al., 1999). However, as shown in this study and in our work, a remarkable difference between this mechanism and the programmed cell death of higher organisms is that dead hyphae from Streptomyces do not completely disappear, but remain to form part of the colony structure, thus allowing the passage of the recycled nutrients. On the other hand, several eukaryotic protein kinases and apoptotic proteins have homologues in Streptomyces (Zhang, 1996; Aravind et al., 1999) and some of the apoptotic nucleases, as also occurs with the $18 \mathrm{kDa}$ and the 20-23 kDa Streptomyces enzymes, have $\mathrm{Mg}^{2+}$ and $\mathrm{Ca}^{2+}$ requirements and are inhibited by high $\mathrm{NaCl}$ or $\mathrm{KCl}$ concentrations, $\mathrm{Zn}^{2+}$ or aurin tricarboxylic acid (Peitsch et al., 1994; Montague \& Cidlowski, 1996; Hale et al., 1996; Hughes \& Cidlowski, 1999; Widlak \& Garrard, 2001). It seems that the study of the biochemical and genetic basis of the programmed cell death in this bacterium could contribute to a better understanding of the role and evolution of this important process in eukaryotic cells.

\section{ACKNOWLEDGEMENTS}

We thank Angel Martinez Nistal, Image Process and Analysis Service of the University of Oviedo for his indispensable assistance with the confocal microscope. This research was supported by grant BIO2000-0577, Plan Nacional de ICDIT, MCT, Spain.

\section{REFERENCES}

Aravind, L., Dixit, V. M. \& Koonin, E. V. (1999). The domains of death: evolution of the apoptosis machinery. Trends Biochem Sci 24, 47-53.

Baltz, R. H. (1998). Genetic manipulation of antibiotic-producing Streptomyces. Trends Biochem Sci 6, 76-83.

Cal, S., Aparicio, J. F., De los Reyes-Gavilán, C. G., Nicieza, R. G. \& Sánchez, J. (1995). A novel exocytoplasmic endonuclease from Streptomyces antibioticus. Biochem J 306, 93-100.

Chater, K. F. (1998). Taking a genetic scalpel to the Streptomyces colony. Microbiology 144, 1465-1478.

Fernández, M. \& Sánchez, J. (2001). Viability staining and terminal deoxyribonucleotide transferase-mediated dUTP nick end labeling of the mycelium in submerged cultures of Streptomyces antibioticus ETH7451. J Microbiol Methods 47, 293-299.

Fernández, M., Olek, A., Walter, J. \& Sánchez, J. (1998). Analysis of DNA methylation processes related to the inhibition of DNA synthesis by 5 -azacytidine in Streptomyces antibioticus ETH7451. Biol Chem 379, 559-562.

Granozzi, C., Billeta, R., Passantino, R., Sollazzo, M. \& Puglia, A. M. (1990). A breakdown in macromolecular synthesis preceding differentiation in Streptomyces coelicolor A3(2). J Gen Microbiol 136, 713-716.

Hale, A. J., Smith, C. A., Sutherland, L. C., Stoneman, V. E. A., Longthorne, V. L., Culhane, A.C. \& Williams, G. T. (1996). Apoptosis: molecular regulation of cell death. Eur J Biochem 236, $1-26$.

Hochman, A. (1997). Programmed cell death in prokaryotes. Crit Rev Microbiol 23, 207-214. 
Hughes, F. M. \& Cidlowski, J. A. (1999). Potassium is a critical regulator of apoptotic enzymes in vitro and in vivo. Adv Enzyme Regul 39, 157-171.

Laemmli, U. K. (1970). Cleavage of structural proteins during the assembly of the head of bacteriophage T4. Nature 227, 680-685.

Mendez, C., Braña, A. F., Manzanal, M. B. \& Hardisson, C. (1985). Role of substrate mycelium in colony development in Streptomyces. Can J Microbiol 31, 446-450.

Miguelez, E. M., Hardisson, C. \& Manzanal, M. B. (1999). Hyphal death during colony development in Streptomyces antibioticus: morphological evidence for the existence of a process of cell deletion equivalent to apoptosis in a multicellular prokaryote. $J$ Cell Biol 145, 515-525.

Montague, J. W. \& Cidlowski, J. A. (1996). Cellular catabolism in apoptosis: DNA degradation and endonuclease activation. Experientia 52, 957-962.

Nicieza, R. G., Huergo, J., Connolly, B. A. \& Sánchez, J. (1999). Purification, characterization and role of nucleases and serine proteases in Streptomyces differentiation: analogies with the biochemical processes described in late-steps of eukaryotic apoptosis. J Biol Chem 274, 20366-20375.
Novella, I. S., Barbés, C. \& Sánchez, J. (1992). Sporulation of Streptomyces antibioticus ETHZ 7451 in submerged culture. Can J Microbiol 38, 769-773.

Peitsch, M. C., Mannherz, X. G. \& Tschopp, J. (1994). The apoptosis endonucleases: cleaning up after cell death? Trends Cell Biol 4, 37-41.

Rosenthal, A. \& Lacks, S. A. (1977). Nuclease detection in SDSpolyacrylamide gel electrophoresis. Anal Biochem 80, 76-90.

Smith, R. J. (1995). Calcium and bacteria. Adv Microb Physiol 37, 83-103.

Widlak, P. \& Garrard, W. T. (2001). Ionic and cofactor requirements for the activity of the apoptotic endonuclease DFF40/CAD. Mol Cell Biochem 218, 125-130.

Yarmolinsky, M. B. (1995). Programmed cell death in bacterial populations. Science 267, 836-837.

Zhang, C.-C. (1996). Bacterial signalling involving eukaryotic-type protein kinases. Mol Microbiol 20, 9-15.

Received 27 June 2001; revised 14 September 2001; accepted 4 October 2001. 